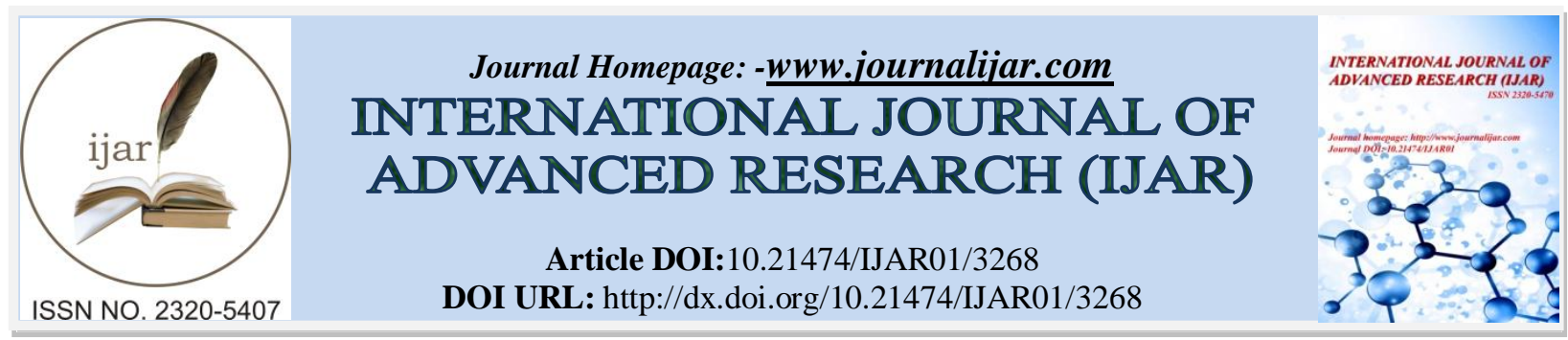

RESEARCH ARTICLE

\title{
VAGINAL MALIGNANT MELANOMA IN TREATED PATIENT OF CARCINOMA CERVIX- AN UNUSUAL CLINICALENTITY.
}

\author{
Divyesh Kumar ${ }^{1}$, Anindya Mukherjee ${ }^{1}$, Manish Rohilla ${ }^{2}$, Nalini Gupta ${ }^{2}$, Bhavana Rai ${ }^{1}$ and Sushmita \\ Ghoshal ${ }^{1}$. \\ 1. Department of Radiotherapy, PGIMER, Chandigarh. \\ 2. Department of Cytopathology, PGIMER, Chandigarh.
}

\section{Manuscript Info}

\section{Manuscript History}

Received: 02 December 2016

Final Accepted: 05 January 2017

Published: February 2017

Key words:-

Vaginal malignant melanoma, possibly radiation-induced, rare.

\begin{abstract}
Vaginal melanoma is a rare gynecological malignancy, with no clearly defined risk factor. It presents mostly in postmenopausal women as a painless lump in lower vagina. Surgical excision with or without adjuvant radiotherapy is the treatment of choice. Despite all treatment modalities, it is characterized by its poor survival outcome. There isn't yet any conclusive evidence on the possibility of radiation induced carcinogenesis.
\end{abstract}

\section{Introduction:-}

Vaginal malignant melanoma (VMM) is a rare entity with an estimated incidence of 0.026/100,000 women per year ${ }^{[1]}$. It has a very aggressive clinical course with poor survival outcomes ${ }^{[1]}$. No definite risk factor has yet been identified and prior therapeutic radiotherapy as an etiology is a matter of speculation right now ${ }^{[2]}$. We describe here a case of VMM which developed 6 years after radical radiotherapy for carcinoma cervix.

\section{Case Presentation:-}

A 66 year post-menopausal female resident of Punjab, P 3+0, was referred to our clinic for cervical brachytherapy in early August 2009. She was a diagnosed case of squamous cell carcinoma of cervix, FIGO stage IIB and had received external beam radiotherapy by Cobalt-60 to a dose of 46Gy in 23 fractions, completed in July, 2009. On local examination, a $2 \times 1 \mathrm{~cm}$ residual was seen at cervix with thickened medial one-third of right parametrium;left parametriumand rectal mucosa were free. We treated her with 35 Gy Low Dose Rate (LDR) equivalents by Medium Dose Rate (MDR) Selectron applicator. Post treatment patient had clinically complete response. Hence, she was kept on periodic follow-up and was asymptomatic till December, 2015 when she developed swelling around her genitalia. Local examination revealed a $3.5 \times 2.5 \mathrm{~cm}$ ulcerated growthover upper two-thirds of anterior vaginal wall which bled to touch. The cervix was completely flushed with no evidence of any disease recurrence and bilateral parametrium were fibrosed. Contrast enhanced computed tomography (CECT)chest, abdomen and pelvis showed a well-defined heterogeneous mass $3.5 \times 3.5 \mathrm{~cm}$ involving upper two-thirds of vagina causing circumferential wall thickening ${ }^{\text {[Fig 1] }}$. Three well defined heterogeneously enhancing masses along right external and internal iliac vessels were also seen, suggestive of metastatic lymphadenopathy ${ }^{[\text {Fig }}{ }^{2]}$. Biopsy of the lesion showed predominantly epitheloid tumor cells with large nuclei, vesicular chromatin, prominent nucleoli and scanty to moderate cytoplasm, arranged in sheets in dermis. The cells were extending to deep dermis. Few tumor cells showed intracytoplasmic 
pigmentation. The tumor cells stained positive for HMB-45 and S-100 while negative for pancytokeratin. A pathological diagnosis of nodular melanoma was reported ${ }^{[\mathrm{Fig} 3]}$.

Her general condition was not considered fit for surgery hence palliative radiotherapy (30Gy in 10 fractions) to the primary and inguino-pelvic regions was planned. She tolerated radiotherapy well and vaginal bleeding stopped. Thereafter, she was started on three weekly palliative chemotherapy with cisplatin $\left(30 \mathrm{mg} / \mathrm{m}^{2}\right.$ Day $\left.1-3\right)$ and dacarbazine (375 mg $/ \mathrm{m}^{2}$ Day 1-3). She completed chemotherapy uneventfully. Her last clinical examination showed a marginal decrease in size of of the vaginal mass post treatment.

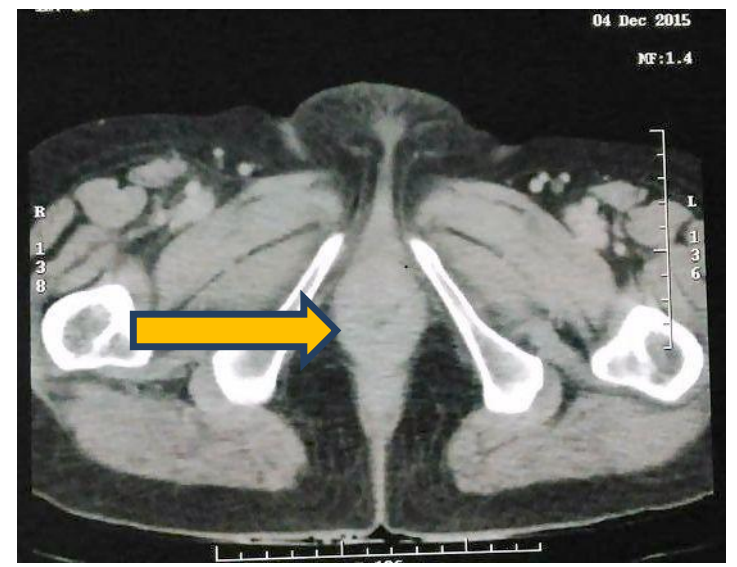

Fig 1:-Well-defined heterogeneous mass involving upper two-thirds of vagina.

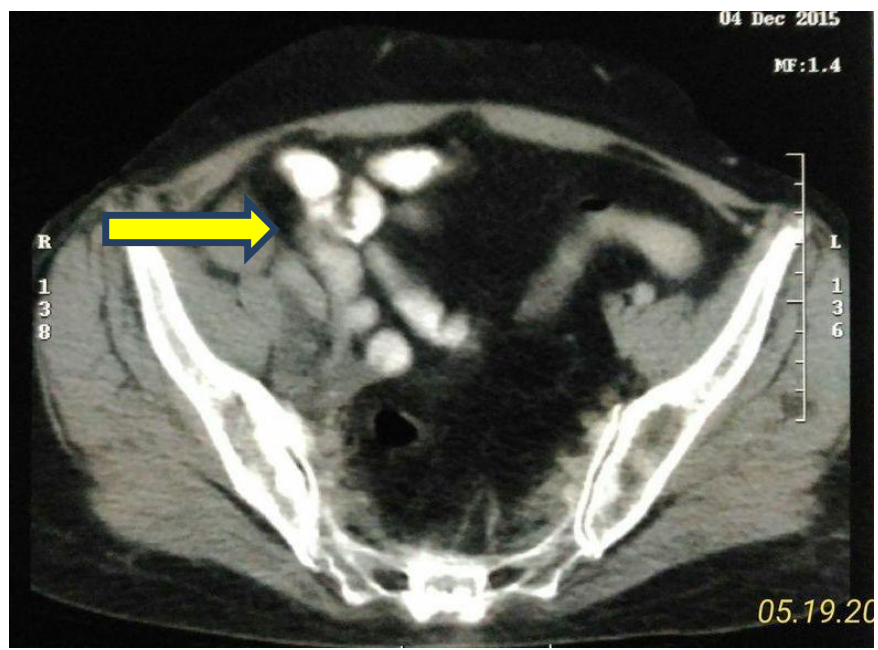

Fig 2:- CECT showing metastatic lymphadenopathy. 


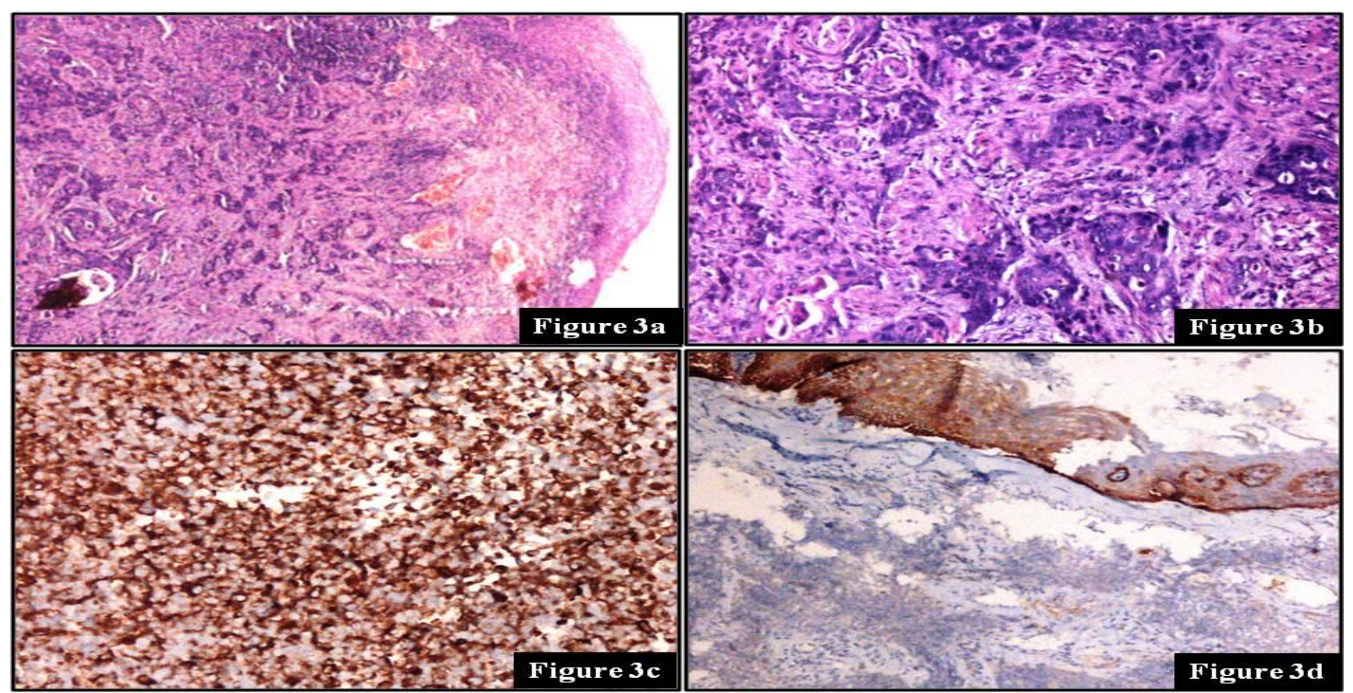

Figure 3a:- Tumor cells in clusters in the dermis. H\&E; 4x Figure 3b: Tumor cells are polygonal, moderately pleomorphic with conspicuous nucleoli. H\&E; 40x Figure 3c: Tumor cells are positive for HMB-45 immunostain; 20x Figure 3d: Tumor cells are negative for pan-cytokeratin immunostain while epidermis is positive; 10x.

\section{Discussion:-}

VMM accounts for less than $3 \%$ of all vaginal malignancies ${ }^{[1]}$.They occur mostly in post-menopausal women in their fifth and sixth decades and commonly present with vaginal bleeding and discharge or with lump in the lower third of vagina or its anterior wall ${ }^{[1,3,4]}$. Macroscopically, VMM are mostly polypoid and ulcerated with a pigmented appearance ${ }^{[3,5]}$. The non-pigmented ones look like epithelial tumors of the vagina ${ }^{[3,5]}$. The most common histopathological variants of VMM are epitheloid (55\%), mixed (28\%) and spindle (17\%) ${ }^{[3,5]}$. In our case, the tumor was ulcerated with a pigmented appearance, located in upper two-thirds of vagina and pathologically it belonged to the mixed variant.

Vaginal melanomas are better staged surgically using the AJCC system, which incorporates Breslow and Clark micro staging ${ }^{[6]}$. Wide local excision (WLE) with negative margins is the standard surgical procedure for VMM ${ }^{[4]}$. Lymph node dissection is not recommended because of the low rate of lymph nodal metastases in such patients ${ }^{[4]}$. Hence, sentinel lymph node biopsy has gained popularity ${ }^{[7]}$. Pelvic exenteration has fallen out of place because of its accompanying morbidity and very modest survival benefit over WLE and adjuvant radiotherapy ${ }^{[4,}{ }^{8}$. Immunotherapy with interferon (IFN) or interleukin-2 (IL-2) has shown survival benefit in VMM, but toxicity of the therapy often excludes its application in elderly patients ${ }^{[9]}$. Combining immunotherapy with chemotherapy (known as 'biochemotherapy') has shown improved response rates over chemotherapy alone in cutaneous melanomas, but its role in VMM is yet to be proved and its toxicity is a major concern ${ }^{[9]}$. Our patient was 66 years old and her general condition was not fit for any surgery or immunotherapy. Hence we treated her with palliative radiotherapy to vagina and inguino-pelvic regions followed by palliative chemotherapy with reduced doses of cisplatin and dacarbazine, even knowing the little benefits these cytotoxic agents had in VMM ${ }^{[10]}$.

Regardless of the treatment modality, the prognosis of VMM is very poor with a 5 year survival estimate of only 5 $25 \%$, becausemost of the cases are diagnosed at a late stage ${ }^{[1,11 \text { and } 12]}$. The rich vascular and lymphatic network is thought to contribute to early tumor spread and metastases ${ }^{[4]}$. Tumor size less than $3 \mathrm{~cm}$ is supposedly the most important prognostic factor for survival, irrespective of the treatment delivered ${ }^{[13]}$. In our case the vault primary was more than $3 \mathrm{~cm}$ and the disease had already spread to external iliac nodes by the time it was detected. Hence palliative treatment was chosen keeping in mind the dismal prognosis of the patient.

The etiology of VMM is not clearly defined and there are no significant racial or ethnic differences in its incidence ${ }^{[2]}$. Exposure to Ultraviolet radiation has been clearly linked with cutaneous melanomas ${ }^{[14]}$; however, whether therapeutic radiotherapy can be a risk factor for melanomas has not yet been documented clinically. With extensive search, we could find only one molecular medicine research article reporting that radiotherapy induced decrease in substance $\mathrm{P}$ may potentiate melanoma growth ${ }^{[15]}$. We are not sure whether radiotherapy induced changes in immune 
environment in melanocytes of vaginal mucosa is implicated in the development of VMM in our case, but the link can't be rejected either.

\section{Conclusion:-}

At this moment we can suggest thatvaginal melanoma may be a possible clinical entity as a late sequlae of radiation therapy, which can only be substantiated with further case reports in future.

\section{References:-}

1. M. A.Weinstock, "Malignantmelanoma of the vulva and vagina in theUnited States: patterns of incidence and population-based estimates of survival," The American Journal of Obstetrics andGynecology, vol. 171, no. 5, pp. 1225-1230, 1994.

2. D.-N. Hu, G.-P.Yu, and S. A. McCormick, "Population-based incidence of vulvar and vaginal melanoma in various races and ethnic groups with comparisons to other site-specific melanomas," Melanoma Research, vol. 20, no. 2, pp. 153-158, 2010.

3. Gupta D, Malpica A, Deavers MT and Silva EG: Vaginal melanoma: a clinicopathologic and immunohistochemical study of 26 cases. Am J SurgPathol 26: 1450-1457, 2002.

4. Miner TJ, Delgado R, Zeisler J, et al: Primary vaginal melanoma: a critical analysis of therapy. Ann SurgOncol 11: 34-39, 2004.

5. G. Borazjani, K. A. Prem, T. Okagaki, L. B. Twiggs, and L. L. Adcock, "Primarymalignant melanoma of the vagina: a clinicopathological analysis of 10 cases," Gynecologic Oncology, vol. 37, no. 2, pp. 264-267, 1990.

6. https://cancerstaging.org/references-tools/quickreferences/documents/melanomasmall.pdf

7. L. Abramova, J. Parekh, W. P. Irvin Jr. et al., "Sentinel node biopsy in vulvar and vaginal melanoma: presentation of six cases and a literature review," Annals of Surgical Oncology, vol. 9, no. 9, pp. 840-846, 2002.

8. Frumovitz M, Etchepareborda M, Sun CC, et al: Primary malignant melanoma of the vagina. Obstetrics and Gynecology 116: 1358-1365, 2010.

9. N. J. Ives, R. L. Stowe, P. Lorigan, andK. Wheatley, "Chemotherapy compared with biochemotherapy for the treatment ofmetastatic melanoma: a meta-analysis of 18 trials involving 2,621 patients," Journal of Clinical Oncology, vol. 25, no. 34, pp. 5426- 5434, 2007.

10. Harting MS and Kim KB: Biochemotherapy in patients with advanced vulvo-vaginal mucosal melanoma. Melanoma Res 14: 517-520, 2004

11. Androutsopoulos G, Adonakis G, Ravazoula P, Kourounis G. Primary malignant melanoma of vagina: A case report. Eur J GynaecolOncol 2005;26:661-2.

12. Tjalma WA, Monagham JM, de Barros Lopes A, Naik R, Nordin A. Primary vaginal melanoma and long term survivors. Eur J GynaecolOncol 2001;22:20-2.

13. G.C. Reid, R.W. Schmidt, J. A. Roberts, M. P.Hopkins, R. J. Barrett, andG.W.Morley, "Primarymelanoma of the vagina: a clinicopathologic analysis," Obstetrics and Gynecology, vol. 74,no.2 pp. 190-199, 1989.

14. Jhappan C., Noonan Frances P and Merlino G. Ultraviolet radiation and cutaneous malignant melanoma. Oncogene (2003) 22, 3099-3112

15. Korcum A Fidan, Sanlioglu S, Aksu Get al. Radiotherapy-induced decreases in substance P levelsmay potentiate melanoma growth. Molecular medicine reports 2: 319-326, 2009. 